\title{
Preparation and Characterization of a Gastric Floating Dosage Form of Capecitabine
}

\author{
Ehsan Taghizadeh Davoudi, ${ }^{1}$ Mohamed Ibrahim Noordin, ${ }^{1}$ Ali Kadivar, ${ }^{1}$ \\ Behnam Kamalidehghan, ${ }^{1}$ Abdoreza Soleimani Farjam, ${ }^{2}$ and Hamid Akbari Javar ${ }^{3}$ \\ ${ }^{1}$ Department of Pharmacy, Faculty of Medicine, Universiti of Malaya, 50603 Kuala Lumpur, Malaysia \\ ${ }^{2}$ Institute of Tropical Agriculture, Universiti Putra Malaysia (UPM), 43400 Selangor, Serdang, Malaysia \\ ${ }^{3}$ Department of Pharmaceutics, Faculty of Pharmacy, Tehran University of Medical Sciences (TUMS), Tehran, Iran
}

Correspondence should be addressed to Hamid Akbari Javar; akbarijo@sina.tums.ac.ir

Received 30 May 2013; Accepted 8 July 2013

Academic Editor: Ibrahim Banat

Copyright (C) 2013 Ehsan Taghizadeh Davoudi et al. This is an open access article distributed under the Creative Commons Attribution License, which permits unrestricted use, distribution, and reproduction in any medium, provided the original work is properly cited.

\begin{abstract}
Gastrointestinal disturbances, such as nausea and vomiting, are considered amongst the main adverse effects associated with oral anticancer drugs due to their fast release in the gastrointestinal tract (GIT). Sustained release formulations with proper release profiles can overcome some side effects of conventional formulations. The current study was designed to prepare sustained release tablets of Capecitabine, which is approved by the Food and Drug Administration (FDA) for the treatment of advanced breast cancer, using hydroxypropyl methylcellulose (HPMC), carbomer934P, sodium alginate, and sodium bicarbonate. Tablets were prepared using the wet granulation method and characterized such that floating lag time, total floating time, hardness, friability, drug content, weight uniformity, and in vitro drug release were investigated. The sustained release tablets showed good hardness and passed the friability test. The tablets' floating lag time was determined to be 30-200 seconds, and it floated more than 24 hours and released the drug for 24 hours. Then, the stability test was done and compared with the initial samples. In conclusion, by adjusting the right ratios of the excipients including release-retarding gel-forming polymers like HPMC K4M, Na alginate, carbomer934P, and sodium bicarbonate, sustained release Capecitabine floating tablet was formulated.
\end{abstract}

\section{Introduction}

After cardiovascular disease, cancer is the second reason for death. Prostate, lung, colon, and breast cancers are the most common forms of cancer. The present treatments for cancer include surgery, chemotherapy, hormone therapy, gene therapy, and radiation therapy. Currently, chemotherapeutic drugs are the most common type of cancer treatment. However, the administration of high doses of these drugs leads to some adverse toxic effects. As some reports indicated, many side effects, such as systemic side effects, diarrhea, and gastrointestinal problems will appear in anticancer therapy [1-5].

Many drugs, such as Anthracyclines, Taxanes (Docetaxel, Paclitaxel), Gemcitabine, Vinorelbine, Carboplatin, Trastuzumab, Lapatinib, Cyclophosphamide, Methotrexate,
Adriamycin, Epirubicin, Mitoxantrone, Bevacizumab, and Capecitabine, are used in breast cancer. The use of these drugs is strongly recommended to make sure that the side effects and high dosage of these drugs are balanced $[4,6-8]$.

Capecitabine, $5^{\prime}$-deoxy-5-fluoro-N-((pentyloxy) carbonyl)cytidine, is a fluoropyrimidine carbamate which has an antineoplastic activity. This chemical is a prodrug of $5^{\prime}$-deoxy-5fluorouridine ( $5^{\prime}$-DFUR), which is enzymatically converted in vivo to 5 -fluorouracil (5-FU). The commercial brand name is Xeloda, which has a biconvex face and a coated film (such as a light peach-colored film for $150 \mathrm{mg}$ Capecitabine and peach-colored film for $500 \mathrm{mg}$ Capecitabine). But both tablets have the same inactive excipients: hydroxypropyl methylcellulose, Croscarmellose sodium, magnesium stearate, microcrystalline cellulose, anhydrous lactose, and purified water. Also, the light peach- or peach-colored film contains talc, 
TABLE 1: Different formulations of tablets with different concentrations (\%).

\begin{tabular}{|c|c|c|c|c|c|c|c|c|c|}
\hline & HPMC & S.A & Car & S.B & $\mathrm{Lac}$ & PEG & Mg.St & Cap & Total \\
\hline $\mathrm{F} 1$ & 20 & 20 & 1.6 & 13.3 & 35 & 6.6 & 3.3 & 150 & 300 \\
\hline F2 & 20 & 20 & 3.3 & 13.3 & 33.3 & 6.6 & 3.3 & 150 & 300 \\
\hline F3 & 20 & 20 & 4.6 & 13.3 & 32 & 6.6 & 3.3 & 150 & 300 \\
\hline F4 & 16.6 & 16.6 & 3.3 & 13.3 & 40 & 6.6 & 3.3 & 150 & 300 \\
\hline F5 & 16.6 & 20 & 3.3 & 13.3 & 36.6 & 6.6 & 3.3 & 150 & 300 \\
\hline F6 & 16.6 & 23.3 & 3.3 & 13.3 & 33.3 & 6.6 & 3.3 & 150 & 300 \\
\hline F7 & 20 & 16.6 & 3.3 & 13.3 & 36.6 & 6.6 & 3.3 & 150 & 300 \\
\hline F8 & 20 & 20 & 3.3 & 13.3 & 33.3 & 6.6 & 3.3 & 150 & 300 \\
\hline F9 & 20 & 23.3 & 3.3 & 13.3 & 30 & 6.6 & 3.3 & 150 & 300 \\
\hline F10 & 23.3 & 16.6 & 3.3 & 13.3 & 33.3 & 6.6 & 3.3 & 150 & 300 \\
\hline F11 & 23.3 & 20 & 3.3 & 13.3 & 30 & 6.6 & 3.3 & 150 & 300 \\
\hline F12 & 23.3 & 23.3 & 3.3 & 13.3 & 26.6 & 6.6 & 3.3 & 150 & 300 \\
\hline
\end{tabular}

hydroxypropyl methylcellulose, titanium dioxide, and red and yellow iron oxides [9].

Important problems of Capecitabine as to the current clinical treatment are a short half-life and its rapid metabolism in the liver. Therefore, the administration of high doses of Capecitabine leads to some undesirable side effects [10]. All these problems can be resolved using sustained release. Based on previous research, since the advantages of these systems are to achieve the therapeutic concentration, the desired drug release rate prolonged drug release and reduction of the repeating dosage. Many of these problems can be resolved if sustained release is done $[10,11]$.

Sustained release (SR) tablets of anticancer drugs could not only provide an optimum plasma concentration with less frequent administration but also help decrease the side effects of conventional dosage forms, such as GIT problems [12]. This could increase the safe administration and improve patient compliance. Nowadays, some pharmaceutical products are considered as controlled-release, which can also be an effective way to deliver different types of drugs into the tissues or cells, such as diltiazem hydrochloride, chlorpheniramine maleate, ciprofloxacin, theophylline, famotidine, and captopril $[5,13-16]$.

There are several advantages to making sustained release antineoplastic drugs like Capecitabine. These drugs show fewer side effects, have longer half-lives, require less frequent dosages, and improve efficacy. Thus, there would be better patient compliance and less variation in plasma/blood levels [17]. The gastroretentive drug delivery system is formulated to keep the tablet in the stomach for several hours and can improve the drug's solubility and bioavailability and reduce drug waste $[5,18]$. This study aimed to prepare the floating dosage form of anticancer drugs, to characterize the sustained release tablet in terms of total floating time, dissolution, friability, hardness, drug content, and weight uniformity, to compare the prepared formulation with the commercial tablet in terms of drug release, and to evaluate the stability of the formulation by accelerating and long term condition according to the International Conference on Harmonization $(\mathrm{ICH})$ procedure.

\section{Materials and Methods}

2.1. Materials. Capecitabine was a kind gift from Osvah Pharmaceutical Company (Tehran, Iran). The $5 \mathrm{FU}$ was provided from sigma Aldrich (KL, Malaysia). HPMC K4M was supplied by Sigma Chemicals. Sodium alginate and sodium bicarbonate were purchased from R\&M chemicals (KL, Malaysia),carbomer934p was purchased from Noveon, polyethylene glycol 3500 from Merck, magnesium stearate from Mallinckrodt, and lactose from $\mathrm{HMbG}$ chemicals (United State of America). All reagents were of analytical or pharmaceutical grade.

\subsection{Methods}

2.2.1. Preparation of Sustained Release Capecitabine. Sustained release tablets were formulated with different types and ratios of polymers using the wet granulation method, and then tablets were compressed directly by a single punch machine. Capecitabine was mixed with carbomer934p as a control release agent, with HPMC K4M as a binder, sodium alginate for gel forming, and sodium bicarbonate to extend floating time. All components were mixed for $10 \mathrm{~min}$, and then Isopropyl alcohol was added dropwise to make a good wet mass of granules. After remixing for $5 \mathrm{~min}$, the granules were passed through a $400 \mu \mathrm{m}$ mesh sieve. Wet granules were put in a $40^{\circ} \mathrm{C}$ oven for $40 \mathrm{~min}$ to become dry, and then PEG 3500 and magnesium stearate were added to the granules as lubricating agents. Eventually, $300 \mathrm{mg}$ of the mixture was weighted and compressed on an $8 \mathrm{~mm}$ flat face by a single punch machine. In this study, 12 formulations were designed with $150 \mathrm{mg}$ of Capecitabine, and the different ratios of polymers are as shown in Table 1 .

2.2.2. Kinetic Modeling of Release Profiles. The dissolution results of all formulations in $0.1 \mathrm{~N} \mathrm{HCl}$ were specified to Higuchi, Korsmeyer-Peppas, Hixson-Crowell, Weibull, and first order and zero order kinetic models. The model with the maximum correlation coefficient was considered to be the best model [19-24]. 
2.2.3. Determination of Floating Lag Time and Total Floating Time. The floating lag time (FLT) is the time taken for a tablet to rise on medium surface, and total floating time (TFT) is the floating duration that a tablet remained on surface. To determine the floating lag time, tablets $(n=4)$ were put on $100 \mathrm{~mL}$ of $0.1 \mathrm{~N} \mathrm{HCL}$ in a beaker, and the time is required for a tablet to rise on surface was measured. Then, the duration of each formulation that remained on the surface was determined as total floating $[15,25]$.

2.2.4. Tablet Hardness. To evaluate tablet hardness, 10 tablets of each formulation were tested for diametrical crushing strength using a hardness tester (Dr. schleuniger, 6D-Tablet Tester).

2.2.5. Tablet Friability. The friability of the SR tablets $(n=10)$ was tested by a friabilator (ERWEKA, TAR 10), at a speed of $100 \mathrm{rpm}$ for 5 minutes.

Hardness and friability values were determined and reported as mean $\pm \mathrm{SD}$.

2.2.6. Drug Content of the Tablets. To evaluate the drug content through a uniformity test, 10 tablets of each formulation were crushed and suspended in $0.1 \mathrm{~N}$ HCL to remove the Capecitabine from the tablets. After 24 hours, media were filtrated and measured by a UV spectrophotometer (Shimadzu $1601)$ at $214 \mathrm{~nm}[26,27]$.

2.2.7. Tablet Weight Uniformity. An electronic balance (Mettler Toledo, 3-MS-S/MS-L, Switzerland) was used to accurately weigh ten tablets which were randomly selected. The results are expressed as mean values \pm SD $[26,27]$.

2.2.8. In Vitro Release Study. A dissolution test was performed for 24 hours using the ERWEKA DT70 dissolution machine according to American pharmacopeia [25]. Each vessel contained $1000 \mathrm{~mL}$ of $0.1 \mathrm{~N} \mathrm{HCL}$; the paddle apparatus with $50 \mathrm{rpm}$ speed was also used, while the temperature was kept stable at $37^{\circ} \mathrm{C}$. Every two hours till 24 hours, $10 \mathrm{~mL}$ of media was withdrawn and measured by UV spectrophotometer at $214 \mathrm{~nm}$ (Shimadzu 1601). Furthermore, $10 \mathrm{~mL}$ of $0.1 \mathrm{~N}$ HCL was replaced to keep the volume stable.

Two formulations (commercial (Xeloda) and prepared tablet) were compared in terms of drug release.

At the end, all results were analyzed using Microsoft Excel. The dissolution test was repeated 4 times for each formulation.

2.2.9. Preparation of Standard Curve. The standard curve was constructed using six different concentrations of Capecitabine, ranging from 100 to $12.5 \mathrm{mg}$. To make a standard curve, $5 \mathrm{mg}$ of Capecitabine was dissolved in $50 \mathrm{~mL}$ of $0.1 \mathrm{~N}$ HCL. Then, $3 \mathrm{~mL}$ of each dilution was measured by UV spectrophotometer (Shimadzu 1601).

2.2.10. Stability Study Test. To study the quality of the finished product under a variety of conditions (time, humidity, and temperature) and to evaluate the formulation, stability studies were prepared for 6 and 12 months according to the ICH
TABLE 2: Storage conditions for tablet stability test.

\begin{tabular}{lcc}
\hline Type of study & Condition & Time \\
\hline Accelerated & $40^{\circ} \mathrm{C} \pm 2^{\circ} \mathrm{C}, 75 \% \mathrm{RH} \pm 5 \% \mathrm{RH}$ & 6 months \\
Long term & $25^{\circ} \mathrm{C} \pm 2^{\circ} \mathrm{C}, 60 \% \mathrm{RH} \pm 5 \% \mathrm{RH}$ & 12 months \\
\hline
\end{tabular}

TABLE 3: Drug release and floating profiles of twelve formulations.

\begin{tabular}{lccc}
\hline Formulation & Release $\%$ & $\begin{array}{c}\text { Floating lag } \\
\text { time }(\mathrm{s})\end{array}$ & $\begin{array}{c}\text { Total floating } \\
\text { time }(\mathrm{h})\end{array}$ \\
\hline F1 & 100 & 30 & 20 \\
F2 & 83.665 & 70 & 24 \\
F3 & 76.3 & 81 & 24 \\
F4 & 100 & 35 & 20 \\
F5 & 90.305 & 45 & 24 \\
F6 & 84.711 & 60 & 24 \\
F7 & 98.286 & 60 & 24 \\
F8 & 83.665 & 70 & 24 \\
F9 & 78.82 & 85 & 24 \\
F10 & 86.666 & 60 & 24 \\
F11 & 80.54 & 80 & 24 \\
F12 & 75.226 & 200 & 0.5 \\
\hline
\end{tabular}

s: second; hr: hour.

(International Conference on Harmonization) procedures. After storage, all samples were analyzed for their physical characterizations.

Tablets $(n=4)$ were used for the stability studies according to ICH long term and accelerated procedure. All tablets were stored in standard condition in WTB binder APT line (Table 2).

All the tablets were packed in polyethylene bags. The bags were clamped using clamping tape and double-packed by putting in cardboard with a plywood lid and the lid was sealed [28-31].

2.2.11. Statistical Analysis. The results were evaluated by oneway analysis of variance (ANOVA) using Duncan's multiple comparison test. Differences were considered significant at $P$ value equal to or less than $0.05[32,33]$.

\section{Results and Discussion}

3.1. Floating Profile. The sustained release Capecitabine floating tablets were developed using release-retarding gelforming polymers HPMC $\mathrm{K} 4 \mathrm{M}, \mathrm{Na}$ alginate, and carbomer934P, accompanied by sodium bicarbonate as a gasforming agent and lactose as filler.

Table 3 shows the results of the floating and releasing times of 12 prepared formulations over 24 hours.

The investigated gastric floating systems employed sodium bicarbonate $\left(\mathrm{NaHCO}_{3}\right)$ as a gas-forming agent, which is trapped in a hydrogel matrix (HPMC K4M and $\mathrm{Na}$ alginate). The in vitro study revealed that most formulations are able to keep the drug buoyant for more than $24 \mathrm{~h}$ (Table 3 ). This suggests that the gel layers, formed by the investigated 
polymers, enabled efficient entrapment of the generated $\mathrm{CO}_{2}$ bubbles.

The floating lag time for most formulations was below 90 seconds, regardless of the content of polymers used (Table 3), indicating significance of the polymers' concentrations (Table 1). The interaction between sodium bicarbonate $\left(\mathrm{NaHCO}_{3}\right)$ as a gas-generating agent and the dissolution medium $\left(0.1 \mathrm{~mol} \mathrm{~L}^{-1} \mathrm{HCl}, \mathrm{pH} 1.2\right)$ generated and entrapped $\mathrm{CO}_{2}$ inside the jellified polymeric matrices, inducing the tablet to float. A decrease in tablet-specific gravity causes the tablet to float on extended residence time in the stomach, improving absorption.

As the amount of carbomer934P increased, TFT decreased - this could be due to the high affinity of carbomer towards water, which promotes water penetration into polymeric matrices, leading to increased density. As the amount of HPMC K4M increased, the total floating time increased-this is because of the increased gel strength of the matrices, which prevents the escape of involved $\mathrm{CO}_{2}$ from the matrices, leading to decreased density. As the amount of SA increased, TFT decreased-this is because of the poor gelling strength of SA compared to HPMC K4M that was previously reported $[34,35]$.

3.2. Drug Release Profiles. Depending on the type and concentration of polymers, variable drug release profiles were successfully tailored.

The dissolution profile of the best formulation (formulation F7) according to standard curve and R2 (Figure 2) was choose and is shown in Figure 1, with appropriate release rate near zero order release kinetic. Drug release involves a combination of swelling, diffusion, and erosion of matrices. This might be due to the water solubility of Capecitabine as well as different characteristics of polymers.

The influence of carbomer934P, HPMC K4M, and $\mathrm{Na}$ alginate on the release of capecitabine from the floating tablets in $0.1 \mathrm{~N} \mathrm{HCl}(\mathrm{pH} 1.2)$ at $37 \pm 0.5^{\circ} \mathrm{C}$ was shown in Figures $3,4,5$, and 6 . It is clear that all formulations succeeded in controlling the rate of drug release. However, the drug release rate was dependent on the type and concentration of the collaborated polymers. A higher concentration of HPMC K4M would promote the formation of highly viscous gels upon contact with aqueous fluids. This would promote retardation of the drug release rates. Siepmann and Peppas [36] suggested that drug release from HPMC matrices is sequentially governed as follows: at the initial time, when the tablet contacts the media, water can penetrate into the polymeric complex, and due to water absorption, HPMC will swell and increase the dimensions of the complex. Then, drug will dissolve and diffuse out due to the concentration of the polymers.

The results of $t_{50}$ (time required for $50 \%$ drug release) showed wide variations. From the results of multiple regression analysis, it was found that the dependent variable, $t_{50}$, is strongly dependent on the independent variables (carbomer934P, HPMC, and Na alginate). As the amount of HPMC K4M and carbomer934P increased, $t_{50}$ decreased and floating lag time increased; again, this may be due to the high affinity of HPMC and carbomer934P towards water, which promotes water penetration into polymeric matrices, leading

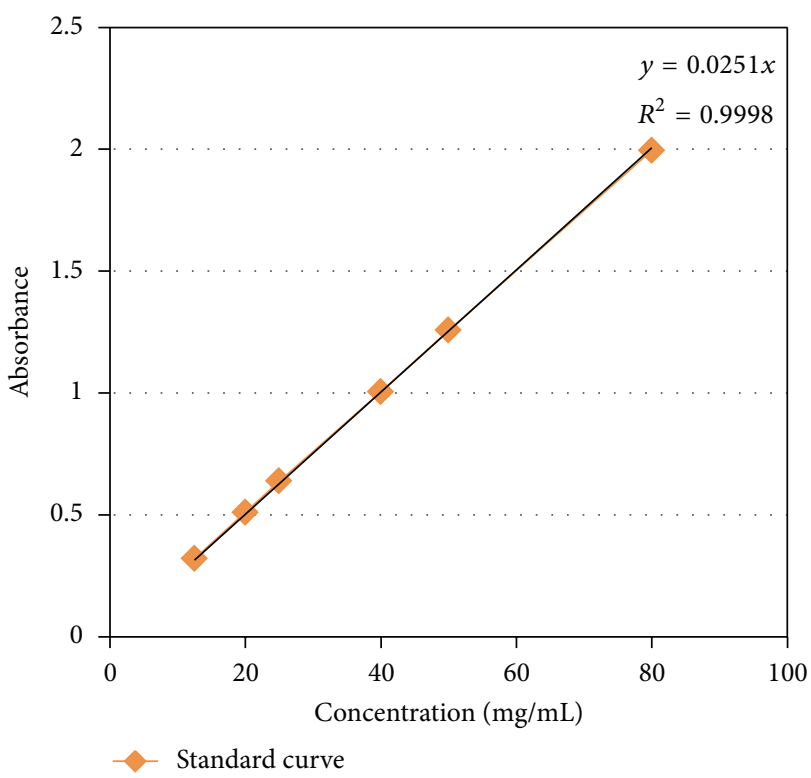

FIGURE 1: Calibration curve of Capecitabine in HCL $0.1 \mathrm{~N}$.

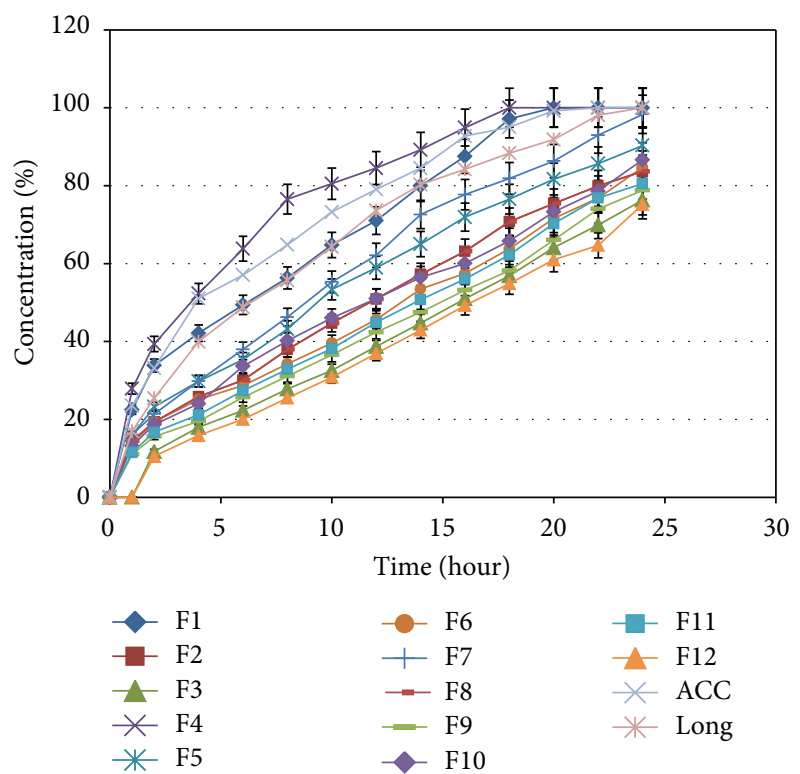

FIGURE 2: In vitro release profiles of various Capecitabine floating formulations in $0.1 \mathrm{~N} \mathrm{HCl}(\mathrm{pH} 1.2)$ at $37 \pm 0.5^{\circ} \mathrm{C}(n=4)$.

to solubility of Capecitabine. As the amount of $\mathrm{Na}$ alginate increased, $t_{50}$ decreased probably because of the poor water affinity of $\mathrm{Na}$ alginate compared to HPMC K4M and carbomer934P.

As this and previous studies $[5,37,38]$ have shown that, upon contact with aqueous media, polymers would produce strong barriers that would effectively reduce the burst release. Taking into consideration the aim of the research of achieving a compromise between excellent floating behavior (short floating lag time and long total floating time) and sustained 
TABLE 4: Mathematical release modeling of sustained release capecitabine floating tablets.

\begin{tabular}{lccccc}
\hline Formulations code & Zero order $R^{2}$ & First order $R^{2}$ & Higuchi $R^{2}$ & Hixson-Crowell $R^{2}$ & Korsmeyer-Peppas \\
\hline F1 & 0.964 & 0.818 & 0.983 & 0.908 & 0.482 \\
F2 & 0.996 & 0.972 & 0.977 & 0.990 & 0.576 \\
F3 & 0.992 & 0.959 & 0.970 & 0.980 & 1.606 \\
F4 & 0.871 & 0.974 & 0.962 & 0.940 & 0.413 \\
F5 & 0.989 & 0.968 & 0.988 & 0.993 & 0.558 \\
F6 & 0.996 & 0.926 & 0.954 & 0.963 & 0.564 \\
F7 & 0.989 & 0.851 & 0.988 & 0.960 & 0.596 \\
F8 & 0.996 & 0.972 & 0.977 & 0.990 & 0.575 \\
F9 & 0.997 & 0.943 & 0.955 & 0.969 & 0.625 \\
F10 & 0.993 & 0.936 & 0.980 & 0.973 & 0.590 \\
F11 & 0.998 & 0.951 & 0.962 & 0.976 & 0.621 \\
F12 & 0.992 & 0.954 & 0.967 & 0.976 & 0.644 \\
Acc & 0.922 & 0.857 & 0.986 & 0.955 & 0.464 \\
Long & 0.955 & 0.894 & 0.997 & 0.46 & \\
\hline
\end{tabular}

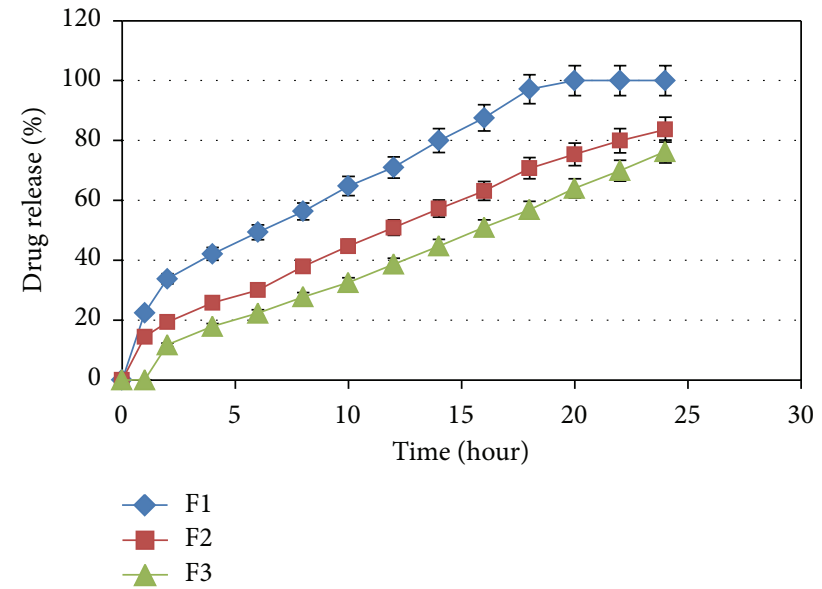

FIGURE 3: The influence of carbomer934P on the release of Capecitabine from the SR tablets in $0.1 \mathrm{~N} \mathrm{HCl}(\mathrm{pH} 1.2)$ at $37 \pm 0.5^{\circ} \mathrm{C}$ $(n=4)$.

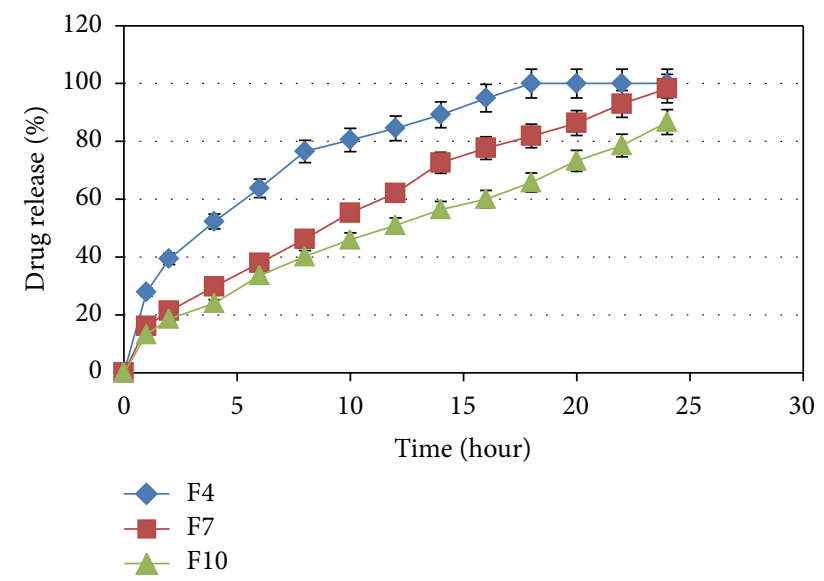

FIGURE 4: The influence of HPMC K4M in F4, F7, and F10 on the release of Capecitabine from the SR tablets in $0.1 \mathrm{~N} \mathrm{HCl}(\mathrm{pH} 1.2)$ at $37 \pm 0.5^{\circ} \mathrm{C}(n=4)$.

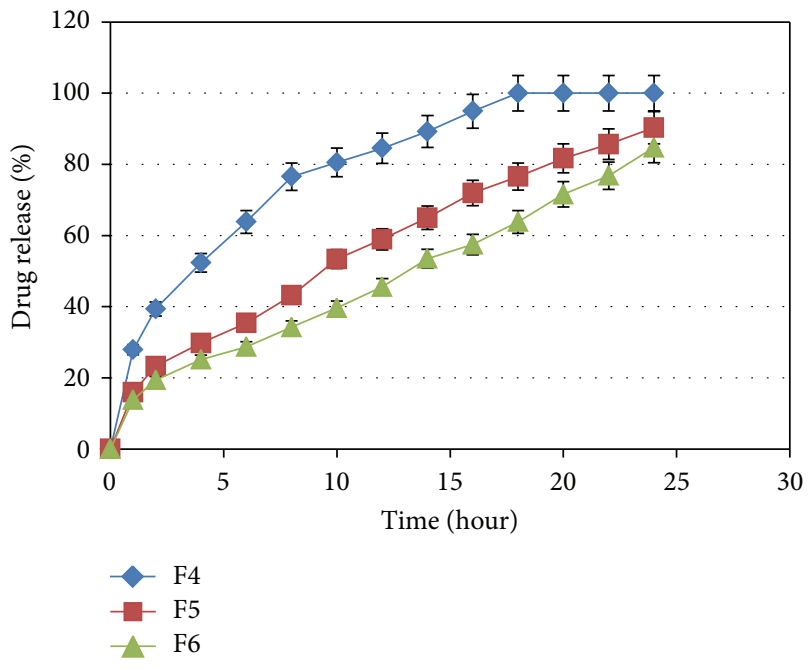

Figure 5: The influence of $\mathrm{Na}$ alginate in F4, F5, and F6 on the release of Capecitabine from the SR tablets in $0.1 \mathrm{~N} \mathrm{HCl}(\mathrm{pH} 1.2)$ at $37 \pm 0.5^{\circ} \mathrm{C}(n=4)$.

drug release characteristics, formula F7 was chosen for further studies.

An immediate release rate was achieved following the dissolution of a commercial brand of Capecitabine $150 \mathrm{mg}$ tablets in $0.1 \mathrm{~N} \mathrm{HCl}$. Indeed, $100 \%$ of the drug was released within $40 \mathrm{~min}$ (Figure 7). There was a significant difference between immediate release and sustained release $(P<0.05)$. The rate of immediate release significantly increased and most of the drug was released within the first 30 minutes, but in sustained release, the drug release increased gradually during 24 hours (Figure 7).

3.3. Kinetic Results. To establish the mechanism of drug release, all data from the dissolution studies of floating tablets were obtained and fitted in kinetic models (Table 4) [19, $23,24,39]$. The correlation coefficient $\left(R^{2}\right)$ was used as an 


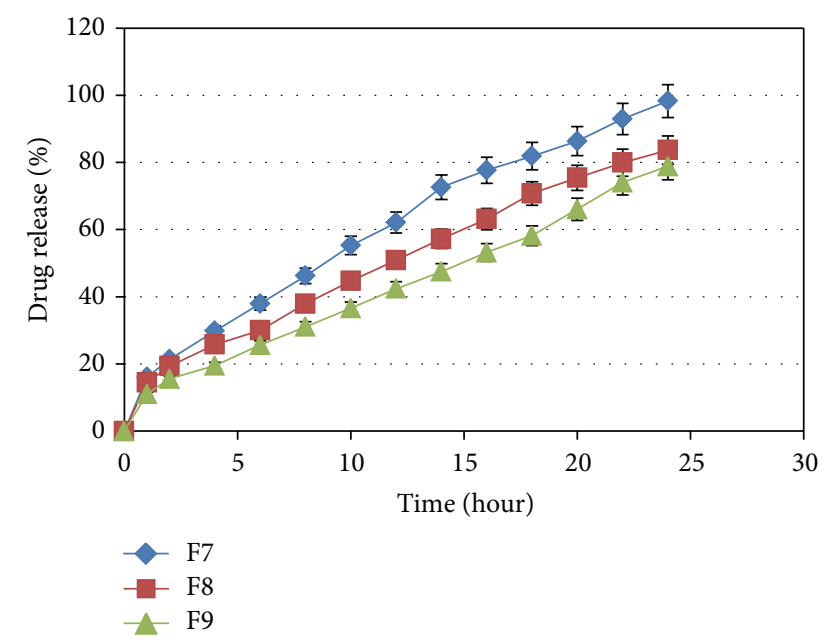

FIGURE 6: The influence of $\mathrm{Na}$ alginate in $\mathrm{F} 7, \mathrm{~F} 8$, and $\mathrm{F} 9$ on the release of Capecitabine from the SR tablets in $0.1 \mathrm{~N} \mathrm{HCl}(\mathrm{pH} 1.2)$ at $37 \pm$ $0.5^{\circ} \mathrm{C}(n=4)$.

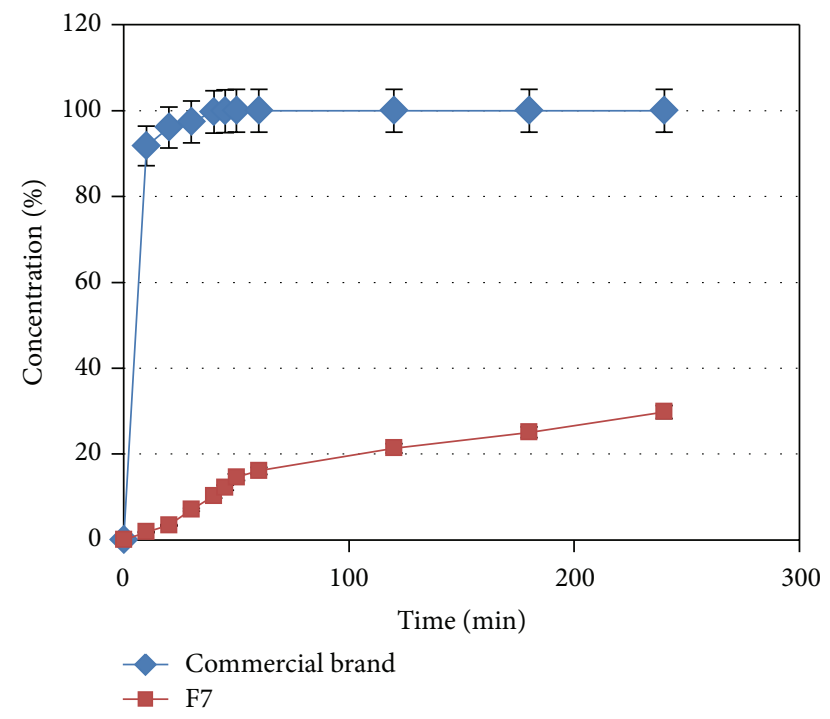

FIGURE 7: Release profiles of a commercial brand of Capecitabine and F7 $(n=4)$.

indicator for best fitting, in which all formulation regression values were between $\left(R^{2}\right)=0.998$ to 0.871 zero order. By comparing the regression values of different models, the zero order model was found to be the best model for optimum formulation (F7) (Table 4). According to the results, it could be predicted that the drug release model of the prepared tablet was of the diffusion type.

3.4. Physical Properties. Previous studies have reported that tablet hardness not only had a slight effect on drug release profiles but was also a determining factor with regards to buoyancy of the tablets. Increasing the hardness would possibly lead to prolongation of the floating lag time by affecting the rate of the tablet penetration by the dissolution medium. Also, the percentage friability for all formulae was less than

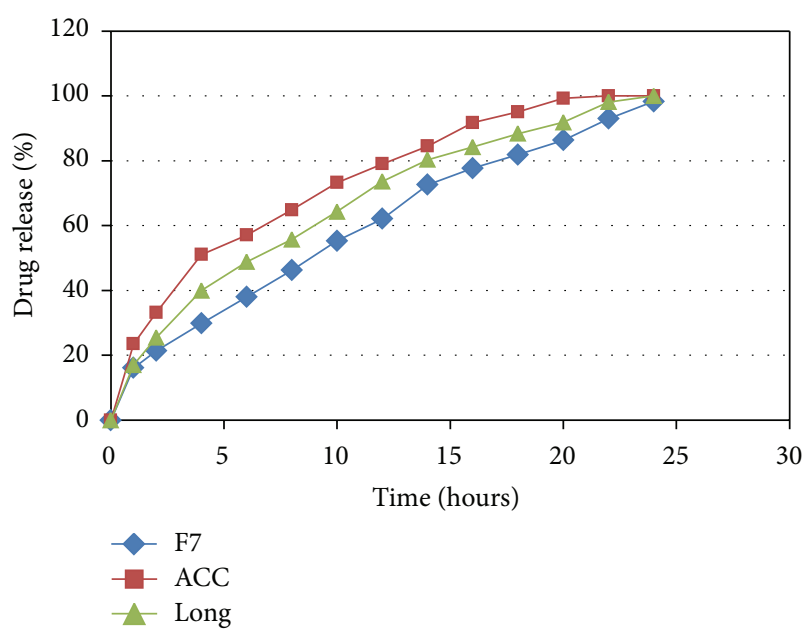

FIGURE 8: Comparison of the release profiles of F7 and stored tablets $(n=4)$.

TABLE 5: Comparison of physical properties of all formulations.

\begin{tabular}{lcccc}
\hline & $\begin{array}{c}\text { Hardness } \\
(\mathrm{N})\end{array}$ & $\begin{array}{c}\text { Friability } \\
(\%)\end{array}$ & $\begin{array}{c}\text { Drug content } \\
(\%)\end{array}$ & $\begin{array}{c}\text { Weight } \\
\text { uniformity }(\mathrm{mg})\end{array}$ \\
\hline F1 & 57 & 0.35 & $99.33 \pm 0.81$ & $299 \pm 0.89$ \\
F2 & 76 & 0.26 & $98.61 \pm 1.13$ & $300 \pm 0.75$ \\
F3 & 81 & 0.22 & $99.45 \pm 0.19$ & $301 \pm 0.82$ \\
F4 & 55 & 0.35 & $99.83 \pm 0.88$ & $298 \pm 1.04$ \\
F5 & 62 & 0.29 & $98.17 \pm 1.05$ & $299 \pm 0.79$ \\
F6 & 68 & 0.25 & $99.05 \pm 0.71$ & $299 \pm 0.9$ \\
F7 & 69 & 0.31 & $99.79 \pm 0.48$ & $299 \pm 0.18$ \\
F8 & 76 & 0.26 & $98.61 \pm 1.13$ & $298 \pm 0.62$ \\
F9 & 80 & 0.21 & $99.86 \pm 0.36$ & $300 \pm 0.25$ \\
F10 & 95 & 0.19 & $99.25 \pm 0.51$ & $298 \pm 0.72$ \\
F11 & 104 & 0.11 & $98.48 \pm 0.19$ & $300 \pm 0.43$ \\
F12 & 112 & 0.103 & $99.01 \pm 0.47$ & $299 \pm 1.09$ \\
\hline
\end{tabular}

$1 \%$, indicating good mechanical resistance. The physicochemical properties of the tablets are as summarized in Table 6.

All tablet formulae showed (Table 5) acceptable physicochemical properties and complied with the pharmacopoeia specifications $[25,26]$ for weight variation, drug content and friability. The weight of the tablets ranged from 298 to $301 \mathrm{mg}$.

Drug uniformity results were found to be good among different formulations, where the percentage of drug content ranged from $98.06 \%$ to $99.86 \%$.

3.5. Drug Release and Physical Profile in Stability Condition. The optimum formulation (F7) was packed according the standard procedures, and was analyzed by dissolution and physical characterization procedures after storage (Tables 2 and 6 and Figure 8).

The drug release of the stored samples was slightly affected by the different storage conditions, indicating that either heat or humidity affected the permeability of the polymeric matrix. 
TABLE 6: Drug release and physical properties of stored tablet.

\begin{tabular}{|c|c|c|c|c|c|c|c|}
\hline Formulation & Release \% & $\begin{array}{c}\text { Floating lag } \\
\text { time }\end{array}$ & $\begin{array}{l}\text { Total floating } \\
\text { time }\end{array}$ & $\begin{array}{l}\text { Hardness } \\
(\mathrm{N})\end{array}$ & $\begin{array}{l}\text { Friability } \\
(\%)\end{array}$ & $\begin{array}{c}\text { Drug content } \\
(\%)\end{array}$ & $\begin{array}{c}\text { Weight } \\
\text { uniformity } \\
(\mathrm{mg})\end{array}$ \\
\hline ACC & 99.216 & $80 \mathrm{~s}$ & $20 \mathrm{~h}$ & 57 & 0.30 & $98.06 \pm 0.61$ & $298 \pm 0.41$ \\
\hline Long & 100 & $65 s$ & $23 \mathrm{~h}$ & 65 & 0.33 & $99.37 \pm 0.82$ & $299 \pm 0.16$ \\
\hline
\end{tabular}

Accelerated test (which carried out at $40^{\circ} \mathrm{C}$ and $75 \%$ humidity) affected the floating ability of tablets by slight decrease in floating time.

3.6. Statistical Analysis Results. Before and after conducting the stability studies, statistical analyses of the results for storage months were carried out by one-way ANOVA. No significant difference $(P$ value $>0.05)$ was observed in the drug release.

F7 stability test after 6 months: there was no significant effect of accelerated term on F7 stability conditions at the $P<$ 0.05 level for the three conditions $(F(1,26)=1.108138, P=$ 0.302173 , and Fcrit $=4.225201)$.

F7 stability test after 12 months: there was no significant effect in release rate and stability of F7 after 12 months at the $P<0.05$ level for the three conditions $(F(1,26)=0.285179$, $P=0.597864$, and Fcrit $=4.225201)$.

F7 stability test in 6 and 12 months: there was no significant effect of 6 months and 12 months on stability condition at the $P<0.05$ level for the three conditions $(F(1,26)=$ $0.260494, P=0.614087$, and Fcrit $=4.225201)$.

\section{Conclusion}

The purpose of this study was to prepare a sustained release tablet of Capecitabine with a 24-hour gradual release with concurrent floating. In doing so, various polymers, such as HPMC K4M, sodium alginate, and sodium bicarbonate, were tested. Also, characterization tests such as floating lag time, total floating time, release measurements, hardness, friability, content uniformity, and weight uniformity were performed. Comparisons of all release studies showed that the drug release depended on the ratio of two polymers-HPMC $\mathrm{K} 4 \mathrm{M}$, which was used as a binder; and sodium alginate, which created gel-forming capabilities in the tablet.

\section{Abbreviations}

$\mu \mathrm{g}: \quad$ Microgram

ACC: Accelerated time

API: Active pharmaceutical ingredient

BP: British pharmacopeia

Cap: Capecitabine

Car: Carbomer934p

FDA: Food and Drug Administration

HPMC: Hydroxypropyl methylcellulose

Lac: Lactose

Long: Long term

mg: Milligram

Mg.St: Magnesium stearate
Min: Minute

mm: Millimeter

${ }^{\circ} \mathrm{C}$ : Degree Celsius

PEG: PolyEthylene glycol

RH: Relative humidity

S.A: Sodium alginate

S.B: Sodium bicarbonate

USP: United States of pharmacopeia

UV: Ultraviolet.

\section{Conflict of Interests}

There is no conflict of interests in this project.

\section{Acknowledgments}

This study was supported by research a Grant from IPPP, Universiti of Malaya, Malaysia (Grant no. PS202/2010B). The authors thank Osvah Pharmaceutical Company, Tehran, Iran, for their gift of Capecitabine and also Mrs. Fatemeh Allah Bedashti for her friendship and assistance.

\section{References}

[1] J. D. Cook, M. Carriaga, S. G. Kahn, W. Schalch, and B. S. Skikne, "Gastric delivery system for iron supplementation," The Lancet, vol. 335, no. 8698, pp. 1136-1139, 1990.

[2] G. J. Yoo, E. G. Levine, C. Aviv, C. Ewing, and A. Au, "Older women, breast cancer, and social support," Supportive Care in Cancer, vol. 18, no. 12, pp. 1521-1530, 2010.

[3] S. Miyazaki, H. Yamaguchi, C. Yokouchi, M. Takada, and W.M. Hou, "Sustained-release and intragastric-floating granules of indomethacin using chitosan in rabbits," Chemical and Pharmaceutical Bulletin, vol. 36, no. 10, pp. 4033-4038, 1988.

[4] R. C. F. Leonard and T. P. Pwint, "Therapeutic aspect of metastatic breast cancer: chemotherapy," in Metastasis of Breast Cancer, R. E. Mansel, Ed., pp. 373-388, Springer, Berlin, Germany, 2007.

[5] S. Arora, J. Ali, A. Ahuja, R. K. Khar, and S. Baboota, "Floating drug delivery systems: a review," AAPS PharmSciTech, vol. 6, no. 3, pp. 372-390, 2005.

[6] H. A. Gezairy, Guidelines for Management of Breast Cancer, EMRO, 2006.

[7] Minestry of Health Malaysia, Clinical Practice Guidlines: Management of Breast Cancer, Minestry of Health Malaysia, Putrajaya, Malaysia, 2002.

[8] R. C. F. Leonard and T. P. Pwint, "Therapeutic aspect of metastatic breast cancer: chemotherapy," in Metastasis of Breast Cancer, R. E. Mansel, Ed., pp. 373-388, Springer, Berlin, Germany, 2007.

[9] Roche, Capecitabine, Food and Drug Administration (FDA), London, UK, 2000. 
[10] J. Khurana, Development and Characterization of Polymeric Nanoparticulate Delivery System for Hydrophillic Drug: Gemcitabine, Creighton University, Omaha, Neb, usa, 2009.

[11] S. Patel, "Oral sustained release formulation of anti cancer drug comptothecin using hydroxyl propyle methyl cellulose," 2008, Long Island.

[12] G. B. Jacobson, R. Shinde, C. H. Contag, and R. N. Zare, "Sustained release of drugs dispersed in polymer nanoparticles," Angewandte Chemie, vol. 47, no. 41, pp. 7880-7882, 2008.

[13] A. V. Mayavanshi and S. S. Gajjar, "Floating drug delivery systems to increase gastric retention of drugs: a review," Research Journal of Pharmacy and Technology, vol. 1, no. 4, pp. 345-348, 2008.

[14] C. Sauzet, M. Claeys-Bruno, M. Nicolas, J. Kister, P. Piccerelle, and P. Prinderre, "An innovative floating gastro retentive dosage system: formulation and in vitro evaluation," International Journal of Pharmaceutics, vol. 378, no. 1-2, pp. 23-29, 2009.

[15] M. Jaimini, A. C. Rana, and Y. S. Tanwar, "Formulation and evaluation of famotidine floating tablets," Current Drug Delivery, vol. 4, no. 1, pp. 51-55, 2007.

[16] R. S. Rathi, V. R. Patil, M. M. Patel, B. A. Patil, A. G. Shankhpal, and S. D. Barhate, "Formulation and evaluation of matrix floating tablet of Famotidine," Journal of Pharmacy Research, vol. 2, no. 3, pp. 531-533, 2009.

[17] A. Savaser, Y. Özkan, and A. Isımer, "Preparation and in vitro evaluation of sustained release tablet formulations of diclofenac sodium," Il Farmaco, vol. 60, pp. 171-177, 2005.

[18] H. Garse, M. Vij, M. Yamgar, V. Kadam, and R. Hirlekar, "Formulation and evaluation of a gastroretentive dosage form of labetalol hydrochloride," Archives of Pharmacal Research, vol. 33, no. 3, pp. 405-410, 2010.

[19] D. Ray and A. K. Prusty, "Designing and in-vitro studies of gastric floating tablets of tramadol hydrochloride," International Journal of Applied Pharmaceutics, vol. 2, no. 4, pp. 12-16, 2010.

[20] S. Londhe, S. Gattani, and S. Surana, "Development of floating drug delivery system with biphasic release for verapamil hydrochloride: in vitro and in vivo evaluation," Journal of Pharmaceutical Science and Technology, vol. 2, no. 11, pp. 361-367, 2010.

[21] R. C. Nagarwal, D. N. Ridhurkar, and J. K. Pandit, "In vitro release kinetics and bioavailability of gastroretentive cinnarizine hydrochloride tablet," AAPS PharmSciTech, vol. 18, no. 1, pp. 294-303, 2010.

[22] M. I. Tadros, "Controlled-release effervescent floating matrix tablets of ciprofloxacin hydrochloride: development, optimization and in vitro-in vivo evaluation in healthy human volunteers," European Journal of Pharmaceutics and Biopharmaceutics, vol. 74, no. 2, pp. 332-339, 2010.

[23] V. S. Patil, P. D. Gaikwad, V. H. Bankar, and S. P. Pawar, "Formulation and evaluation of floating matrix tablet of locally acting h2-antagonist," International Journal of Pharmacy \& Technology, vol. 2, no. 3, pp. 528-540, 2010.

[24] S. Zeenath, R. Gannu, S. Bandari, and M. Y. Rao, "Development of gastroretentive systems for famotidine: in vitro characterization," Acta Pharmaceutica Sciencia, vol. 52, no. 4, pp. 494-504, 2010.

[25] United States Pharmacopeia, USP32-NF27, vol. 2, The United States Pharmacopeial Convention, 2010.

[26] British Pharmacopoeia, Uniformity of Content, Volume 5, Stationery Office on Behalf of the (MHRA), London, UK, 2010.

[27] A. Pare, S. K. Yadav, and U. K. Patil, "Formulation and evaluation of effervescent floating tablet of amlodipine besylate,"
Research Journal of Pharmacy and Technology, vol. 1, no. 4, pp. 526-530, 2008.

[28] I. Ahmad and R. H. Shaikh, "Effect of temperature and humidity on hardness and friability of packaged Paracetamol tablet formulations," Pakistan Journal of Pharmaceutical Sciences, vol. 7, no. 2, pp. 69-78, 1994.

[29] K. A. Russo, "The Role of USP Monographs in Stability Testing," in Pharmaceutical Stability Testing to Support Global Markets: Pharmasp, K. Huynh-Ba, Ed., pp. 51-60, American Association of Pharmaceutical Scientists, Arlington, Va, USA, 2010.

[30] M. Łaszcz, K. Trzcińska, K. Filip, A. Szyprowska, M. Mucha, and P. Krzeczyński, "Stability studies of capecitabine," Journal of Thermal Analysis and Calorimetry, vol. 105, no. 3, pp. 1015-1021, 2011.

[31] U. S. Department of Health and Human Services, Guidance for Industry Q1A(R2) Stability Testing of New Drug Substances and Products, Food and Drug Administration, Silver Spring, Md, USA, 2003.

[32] E. A. Klausner, E. Lavy, D. Stepensky, M. Friedman, and A. Hoffman, "Novel gastroretentive dosage forms: evaluation of gastroretentivity and its effect on riboflavin absorption in dogs," Pharmaceutical Research, vol. 19, no. 10, pp. 1516-1523, 2002.

[33] F. A. A. AI-khaled, "Bioadhesive and floating formulations as sustained release dosage form verapamil hydrochloride," in Pharmaceutics, King Saud University, Riyadh, Saudi Arabia, 2002.

[34] S. El Samaligy, Floating Systems for Oral Controlled Release Drug Delivery, University of Berlin, Berlin, Germany, 2010.

[35] S. T. Prajapati, L. D. Patel, and D. M. Patel, "Gastric floating matrix tablets: design and optimization using combination of polymers," Acta Pharmaceutica, vol. 58, no. 2, pp. 221-229, 2008.

[36] J. Siepmann and N. A. Peppas, "Modeling of drug release from delivery systems based on hydroxypropyl methylcellulose (HPMC)," Advanced Drug Delivery Reviews, vol. 64, pp. 163-174, 2012.

[37] B. Y. Choi, H. J. Park, S. J. Hwang, and J. B. Park, "Preparation of alginate beads for floating drug delivery system: effects of $\mathrm{CO}_{2}$ gas-forming agents," International Journal of Pharmaceutics, vol. 239, no. 1-2, pp. 81-91, 2002.

[38] A. O. Nur and J. S. Zhang, "Captopril floating and/or bioadhesive tablets: design and release kinetics," Drug Development and Industrial Pharmacy, vol. 26, no. 9, pp. 965-969, 2000.

[39] R. C. Nagarwal, D. N. Ridhurkar, and J. K. Pandit, "In vitro release kinetics and bioavailability of gastroretentive cinnarizine hydrochloride tablet," AAPS PharmSciTech, vol. 11, no. 1, pp. 294-303, 2010. 

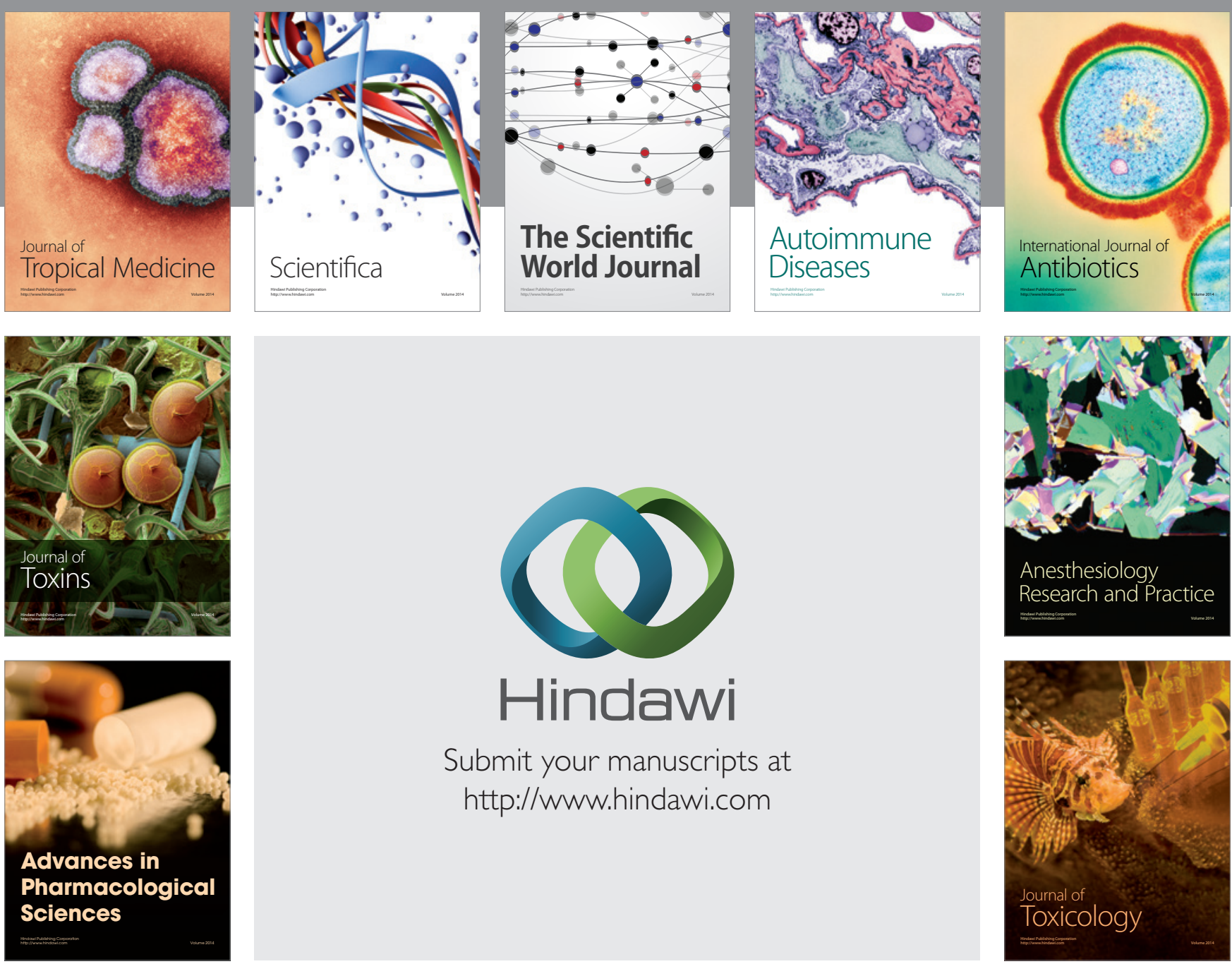

\section{Hindawi}

Submit your manuscripts at

http://www.hindawi.com
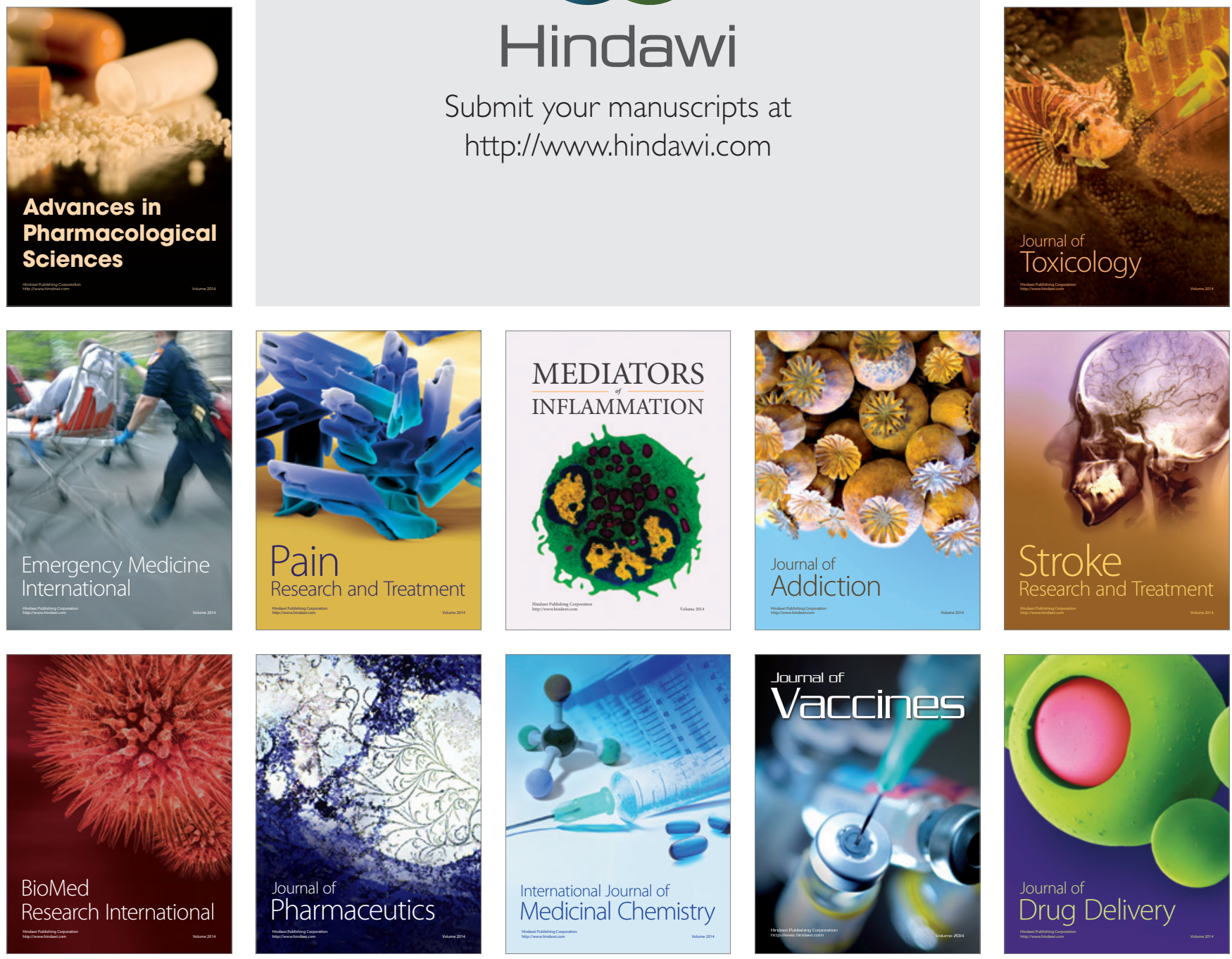